\begin{tabular}{cl|l}
$\begin{array}{c}\text { Cellular Physiology } \\
\text { and Biochemistry }\end{array}$ & Cell Physiol Biochem 2012;30:238-246 & \multicolumn{2}{l}{ DOI: 10.1159/000339060 } & $\begin{array}{l}\text { O 2012 S. Karger AG, Basel } \\
\text { www.karger.com/cpb }\end{array}$ \\
\cline { 2 - 3 } & $\begin{array}{l}\text { Published online: June 19, 2012 } \\
\text { Accepted: May 15, 2012 }\end{array}$ & $1015-8987 / 12 / 0301-0238 \$ 38.00 / 0$
\end{tabular}

\title{
Leptin Affects Insulin Action in Astrocytes and Impairs Insulin-mediated Physical Activity
}

\author{
Tina Sartorius ${ }^{1,2^{\star}}$ Martin Heni ${ }^{1^{\star}}$ Otto Tschritter ${ }^{1}$ Hubert Preiss ${ }^{3,4}$ Sabine \\ Hopp $^{1}$ Andreas Fritsche ${ }^{1,2}$ Paul-Simon Lievertz ${ }^{1} \quad$ Arieh Gertler $^{5}$ Flavien Berthou ${ }^{6}$ \\ Mohammed Taouis ${ }^{6}$ Harald Staiger ${ }^{1}$ Hans-Ulrich Häring ${ }^{1,2}$ Anita M. Hennige ${ }^{1}$
}

\begin{abstract}
${ }^{1}$ University of Tuebingen, Department of Internal Medicine 4, Tuebingen; ${ }^{2}$ Institute for Diabetes Research and Metabolic Diseases of the Helmholtz Centre Munich at the University of Tuebingen, Tuebingen; 'Institute of Medical Psychology and Behavioural Neurobiology, University of Tuebingen, Tuebingen; ${ }^{4}$ Department of Obstetrics and Gynecology, College of Medicine, University of Arkansas for Medical Sciences, Little Rock, AR; ${ }^{5}$ Institute of Biochemistry Food Science and Nutrition, The Robert $\mathrm{H}$. Smith Faculty of Agriculture, Food and Environment, The Hebrew University of Jerusalem, Rehovot; ${ }^{6}$ Laboratoire de Neuroendocrinologie Moléculaire de la Prise Alimentaire, Centre de Neurosciences Paris Sud (CNPS), Orsay; *These authors contributed equally to this work
\end{abstract}

\section{Key Words}

Insulin action • Leptin • Leptin antagonist • Locomotor activity • Mice • Obesity

\begin{abstract}
Background/Aims Impaired insulin action is an early event in the pathogenesis of obesity and type 2-diabetes, and among the metabolic confounders in obese, hyperleptinaemia is constantly present; however its impact on insulin action in the brain and locomotor activity is unknown. Methods We examined insulin action by Western Blot analysis and glycogen synthesis in primary astrocytes and brain tissue and detected locomotion in C57BL/6 mice. The insulinmediated desire to move was evaluated in healthy volunteers and correlated to leptin levels. Results Leptin treatment led to a significant decrease in insulin-mediated phosphorylation of the insulin receptor and Akt 473 which was accompanied by a decline in glycogen synthesis in primary astrocytes and significantly decreased insulin-induced phosphorylation of the insulin receptor and insulin receptor substrate-2 in brain tissues of mice. Intracerebroventricular insulin failed to promote locomotion in the presence of elevated leptin levels. Lean human subjects reported an increase in the desire to move following insulin which failed in obese and there was an inverse correlation between the insulin-mediated desire to move and leptin levels. Conclusions Our data suggest a crosstalk of leptin and insulin in the brain which leads to a decline in locomotor activity. This might represent a molecular mechanism in obese to inhibit physical activity.
\end{abstract}




\begin{tabular}{|c|c|c|}
\hline \multirow{2}{*}{$\begin{array}{l}\text { Cellular Physiology } \\
\text { and Biochemistry }\end{array}$} & \multicolumn{2}{|c|}{ Cell Physiol Biochem 2012;30:238-246 } \\
\hline & $\begin{array}{l}\text { DOI: 10.1159/000339060 } \\
\text { Published online: June 19, } 2012\end{array}$ & $\begin{array}{l}\text { O } 2012 \text { S. Karger AG, Basel } \\
\text { www.karger.com/cpb }\end{array}$ \\
\hline
\end{tabular}

\section{Introduction}

Insulin resistance in the brain is associated with obesity and type 2-diabetes, and neuronspecific knockout models of the insulin receptor or its downstream molecules in mice display obese, physically inactive and insulin resistant phenotypes [1-3]. In turn, in the presence of high fat diet-induced obesity, insulin resistance in the brain develops and is accompanied by a profound decrease in brain activity and physical inactivity [4]. Among the metabolic confounders in obese mice and humans, elevated levels of saturated free fatty acids $[5,6]$ as well as hyperleptinaemia [7-9] are the most prominent with regard to impaired insulin action. We lately identified saturated free fatty acids as a mediator of insulin resistance in the brain that is closely connected to a decline in insulin-mediated brain activity in humans [10].

Besides saturated free fatty acids, leptin out of peripheral fat stores is dramatically increased in obese subjects [11], while by contrast, leptin deficiency in distinct neurons led to an increase in food intake and adiposity. While specific populations of hypothalamic neurons were shown to be leptin sensitive and knockout models displayed striking obese phenotypes, the impact of changes in leptin levels within the physiological range is far less investigated.

In this respect, some neurons were shown to respond across a broad dose range while others displayed limited response within the low range [12]. Therefore, the target for leptin within the physiological range in healthy mice and humans are distinct from those that mediate overfeeding and severe obesity.

In this study, we aimed to identify the impact and molecular mechanism of leptin on insulin action and behaviour in a rather healthy phenotype. Since the insulin and leptin signalling cascades share certain downstream signalling elements $[7,13,14]$, and chronic intracerebroventricular leptin application decreased insulin-mediated phosphorylation of Akt in the hypothalamus of rats [15], we hypothesized that leptin might be a relevant hormone to downregulate insulin action in the brain and affect behaviour like locomotor activity.

First, astrocytes were used to investigate the interaction of leptin and insulin on the molecular level. For a long time, astrocytes were thought to be "bystanders" within the brain; however, recent data provide strong evidence for a role of astrocytes in neurotransmission and information processing in the brain. While neurons perform fast synaptic transmission, astroyctes are responsible for tissue homeostasis, morphological organization and metabolic support, and recent studies provide evidence that neurons and glia are equally important for brain function [16]. With respect to insulin and glucose metabolism, we recently found that human astrocytes are insulin sensitive in terms of glycogen formation and cell proliferation [17] which might translate to brain activity and insulin-mediated locomotion.

Together, our data provide evidence for a role of elevated leptin concentrations in brain metabolism to impair insulin action, glycogen synthesis, brain activity and finally locomotion in mice and humans.

\section{Materials and Methods}

Human astrocytes

Normal Human Astrocytes (NHA, Lonza, Basel, Switzerland) were cultivated as described earlier [17]. Prior to each experiment, cells were starved in DMEM (1g/l glucose, Lonza) $+0.5 \%$ FCS for $24 \mathrm{~h}$. On the RNA level, leptin receptor was detected in a comparable range in human astrocytes than in primary human myotubes. Human recombinant leptin (tebu-bio, Offenbach, Germany) was added (20 or $60 \mathrm{nM}$ ) for another 24h followed by stimulation with human insulin (Novo Nordisk, Bagsvard, Denmark) for 3h (50 $\mathrm{nM}$ ). For Fig. 2a, Leptin was administrated for various times as indicated in the figure. Western-blot analysis 


\section{Cellular Physiology Cell Physiol Biochem 2012;30:238-246 \\ \begin{tabular}{ll|l} 
and Biochemistry & $\begin{array}{l}\text { DOI: 10.1159/000339060 } \\
\text { Published online: June 19, } 2012\end{array}$ & $\begin{array}{l}\text { @ 2012 S. Karger AG, Basel } \\
\text { www.karger.com/cpb }\end{array}$ \\
\hline Sartorius/Heni/Tschritter et
\end{tabular} \\ Sartorius/Heni/Tschritter et al.: Leptin and Insulin Action in Brain}

was performed, and proteins were detected using an anti-phospho-Akt (Ser473, Cell Signaling, Danvers, MA, USA), anti-phospho-Akt (Thr308, Cell Signaling, Danvers, MA, USA), anti-phospho-Stat3 (Tyr705, Cell Signaling, Danvers, MA, USA) or anti-phospho-Gsk3 (Ser9, Upstate, Charlottesville, VA, USA) antibodies. Lysates containing equal amounts of protein were immunoprecipitated with a serine specific antibody to detect serine phosphorylation at 318 in insulin receptor substrate 1 as described earlier [7]. To ensure equal loading, an anti-Akt antibody was used (Cell Signaling, Danvers, MA, USA). Quantification of protein amounts was performed by optical densitometry (Herolab, Wiesloch, Germany).

\section{Primary mouse astrocytes}

One-day-old pubs (C57BL/6NCrl) were used for isolation of primary astrocytes. The medium of the primary astrocyte cultures was changed to glucose-deprived neuronal cell culture medium (1g/l glucose) prior to treatment with leptin $(500 \mathrm{nM})$ for $24 \mathrm{~h}$, human insulin $(100 \mathrm{nM})$ for $3 \mathrm{~h}$, or co-treatment with leptin prior to insulin stimulation. For glycogen synthesis, cells were stimulated with $\mathrm{C}-14$ glucose $(0.2 \mu \mathrm{Ci} / \mu \mathrm{l})$ in parallel with human insulin for $3 \mathrm{~h}$. Western blot experiments were performed in protein lysates using an antibody raised against P-Akt (Ser473, Cell Signaling, Danvers, MA, USA). Quantification of protein amounts was performed using the optical densitometry (Herolab, Wiesloch, Germany).

\section{Animals}

Male C57BL/6NCrl mice at the age of 10 to 12 weeks from Charles River Laboratories were used for in vivo experiments. They were maintained on a $12 \mathrm{~h}$-day/12 h-dark cycle. All procedures were conducted according to the guidelines of laboratory animal care and were approved by the local governmental commission for animal research.

\section{In vivo stimulation and Western blot analysis}

For in vivo stimulation, a bolus of human insulin ( $1 \mathrm{U} /$ mouse for $5 \mathrm{~min})$, mouse leptin $(100 \mu \mathrm{g} / \mathrm{mouse}$ for $30 \mathrm{~min}$, Sigma Aldrich) or leptin (30 min) prior to insulin (5min) was injected into the inferior vena cava of overnight fasted and anesthetized mice. Lysates from total brain containing equal amounts of protein were immunoprecipitated with antibodies directed against IR (kindly provided by R. Lammers, University of Tuebingen, Germany) and Irs2 (Upstate, Charlottesville, USA). Visualization of immunocomplexes after gel electrophoresis and Western blotting were performed using the PY20 antibody (Santa Cruz, La Jolla, CA, USA). Equal protein amounts were verified by using the respective antibodies.

Measurement of locomotor activity and intracerebroventricular application of leptin, insulin and leptin antagonist

Each mouse received an implantable telemetry transmitter and a guide cannula into the lateral ventricle as described earlier [4]. Mice were deprived of food overnight and received a single intracerebroventricular injection of either mouse leptin (10 $\mu \mathrm{g}$ total dose, purchased from Sigma Aldrich), human insulin (3.75 mU total dose, purchased from Novo Nordisk), recombinant mouse leptin antagonist (60 $\mu$ g total dose [18]), vehicle $(0.9 \% \mathrm{NaCl})$, or leptin 30 min prior to insulin. Icv concentrations of leptin and leptin antagonist were adapted as previously published $[15,19]$. Locomotor activity was recorded continuously for $120 \mathrm{~min}$ after injection.

Detection of the desire to move during a hyperinsulinaemic euglycaemic clamp in human subjects

We studied 14 healthy lean (F/M 9/5, age $27 \pm 2$ years, BMI $21 \pm 1 \mathrm{~kg} / \mathrm{m}^{2}$, fasting blood glucose $4.7 \pm 0.1$ $\mathrm{mmol} / \mathrm{l}$, fasting plasma insulin $35 \pm 3 \mathrm{pmol} / \mathrm{l}$, fasting plasma leptin $8.12 \pm 1.7 \mathrm{pg} / \mathrm{ml}$ ) and 32 overweight/ obese humans (F/M 13/19, age $39 \pm 2$ years, BMI $30 \pm 1 \mathrm{~kg} / \mathrm{m}^{2}$, fasting blood glucose $5.1 \pm 0.01 \mathrm{mmol} / \mathrm{l}$, fasting plasma insulin $62 \pm 6 \mathrm{pmol} / \mathrm{l}$, fasting plasma leptin $25.28 \pm 3.34 \mathrm{pg} / \mathrm{ml}(p<0.001$ to lean)). Both groups, lean and obese, underwent medical history, clinical investigation, a standard clinical lab routine and an oral glucose tolerance test. Volunteers who were on pharmacological treatment or had any sign of acute or chronic diseases (including hypertension and diabetes) have been excluded. Informed written consent was obtained from all volunteers prior to the study. The study protocol was approved by the Ethics Committee of the Medical Faculty at the Eberhard-Karls-University in Tuebingen, Germany. The experiment consisted of a 30-min baseline period, and a 90-min hyperinsulinaemic euglycaemic clamp or saline infusion. During the baseline period and after 90 min of insulin or saline infusion, the participants were asked to quantify their desire to move using a visual analog scale ranging from $0 \mathrm{~cm}$ to $10 \mathrm{~cm}$. The difference of change in desire to 


\section{Cellular Physiology and Biochemistry}

Fig. 1. Leptin impairs insulin action in primary mouse and human astrocytes. a Phosphorylation of Akt473 (P-Akt) in primary mouse astrocytes. Cells were treated with insulin, leptin or leptin plus insulin as described in the method section. Representative Western-Blots out of three independent experiments are presented. b Quantification of PAkt is given from four independent experiments, ${ }^{*} p<0.05,{ }^{* *} p<0.005$. $c$ Glycogen synthesis in mouse astrocytes treated with insulin, leptin or leptin followed by insulin, $n=6, \quad{ }^{* *} p<0.005, \quad{ }^{* * *} p<0.001 . \quad \mathrm{d}$ Western Blot analysis (insert) and quantification of P-Akt473 in human astrocytes, $n=6$. ANOVA and the post-hoc test (Tukey-Kramer) with an alpha-level of 0.01 revealed significant differences $\left({ }^{* * *} p<0.001\right)$. e Phosphorylation of Gsk3, Stat3 and Akt at Thr308 in human astrocytes. Cells were treated with insulin, leptin or leptin plus insulin. Representative Western-Blots out of three independent experiments are presented. $\mathrm{f}$ Tyrosine phosphorylation of insulin receptor

a

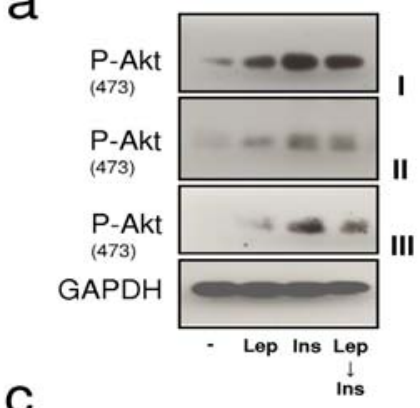

C

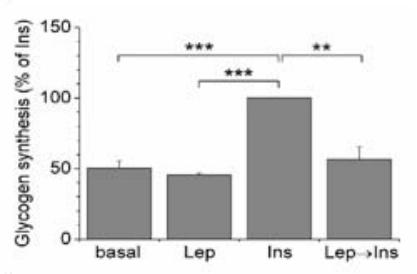

e

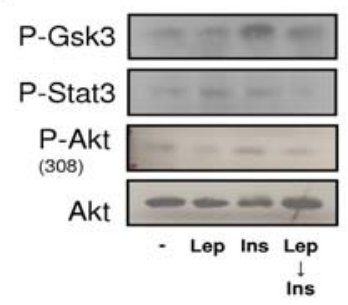

b

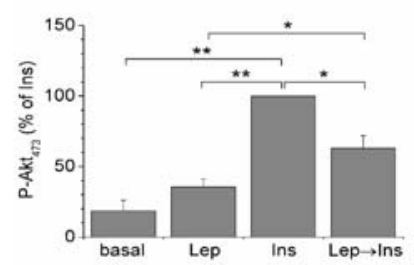

d

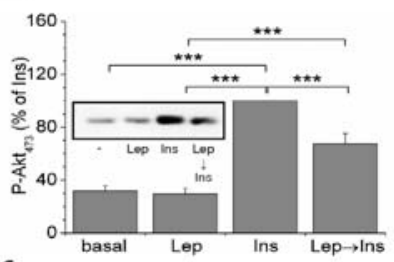

f

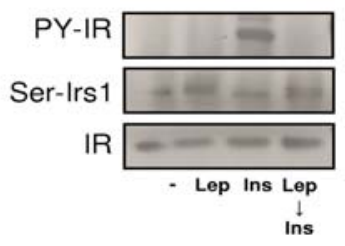
and serine phosphorylation of Irs1 on Ser318 in human astrocytes. Cells were stimulated with insulin, leptin, or leptin followed by insulin. Immunprecipitates were separated by SDS page and probed with the respective antibodies. Equal loading was ensured by reprobing with an anti-insulin receptor antibody. A representative immunoblot is shown out of three independent experiments.

move during the insulin experiment and the change during the saline experiment were calculated. Plasma insulin, leptin and adiponectin concentrations were measured by ELISA (Linco Research, St. Charles, MO, USA). C-reactive protein (CRP) was measured with a standard colorimetric methods using a Roche/Hitachi analyser (Roche Diagnostics, Mannheim, Germany).

\section{Data analysis}

The data analysis was performed as previously described [4]. Data are expressed as mean \pm SEM. Differences between groups were analyzed by one-way ANOVA with post-hoc Tukey Kramer test or twotailed unpaired Student's $t$ test. $P<0.05$ was considered to be statistically significant.

\section{Results}

To identify the role of leptin on insulin action in the brain, primary mouse astrocytes were used. They are known to express insulin and leptin signaling elements $[17,20]$ and represent the major source of energy for neurons by glycogen production. Of note, the expression level of leptin receptor in astrocytes was comparable to primary human myotubes (data not shown).

Leptin pretreatment impaired insulin action downstream of the insulin receptor at the level of Akt-phosphorylation on Serine 473 in primary mouse astrocytes (Fig. 1a and Fig. 1b). The impairment in insulin action went along with a decline in glycogen synthesis in these cells, suggesting that leptin diminishes insulin-mediated glycogen synthesis in these cells (Fig. 1c). In addition, leptin was able to decrease insulin-dependent phosphorylation 


\begin{tabular}{rl|l} 
Cellular Physiology & Cell Physiol Biochem 2012;30:238-246 & \\
\cline { 2 - 3 } and Biochemistry 10.1159/000339060 & $\begin{array}{l}\text { O 2012 S. Karger AG, Basel } \\
\text { www.karger.com/cpb }\end{array}$ \\
\cline { 2 - 3 } & Sartorius/Heni//Tschritter et al:: Leptin and Insulin Action in Brain
\end{tabular}

Fig. 2. Leptin on insulin action in astrocytes depend on time and dose. a Human astrocytes were stimulated with insulin (50 $\mathrm{nM})$, leptin or leptin followed by insulin for $30 \mathrm{~min}$, or 1 , 3,6 and 24 hours. Proteins were separated by SDS-page and Western Blots were probed with antibodies against P-Akt and reprobed with an anti-Akt antibody. b Human astrocytes were treated with either 20 or $60 \mathrm{nM}$ of leptin for 3 hours with and without insulin for 3 hours. A representative Western Blot out of three independent experiments is shown.

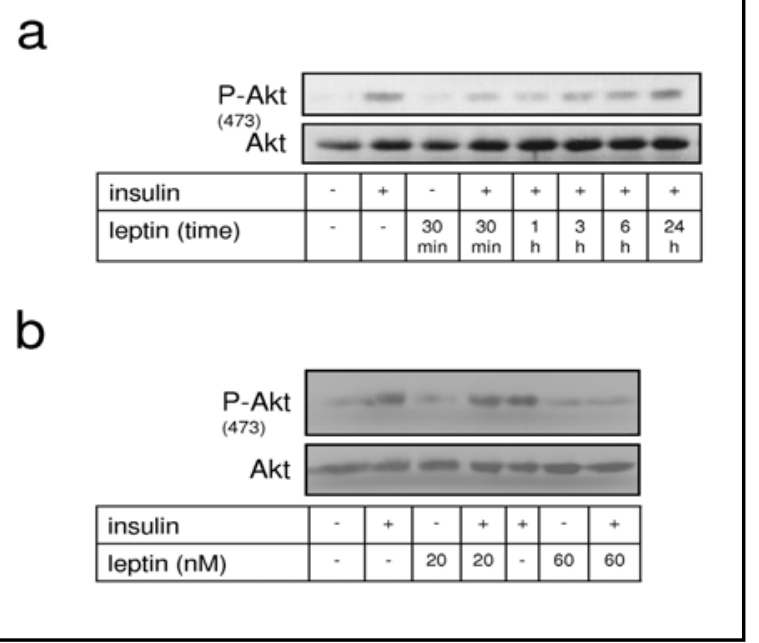

of Akt473 (Fig. 1d) in human astrocytes. Insulin increased phosphorylation of glycogen synthase kinase 3 (Gsk3) while this was absent when cells were preincubated with leptin, and this was also true for the phosphorylation state of signal transducer and activator of transcription 3 (Stat3). By contrast, Akt-phosphorylation on Thr308 was unaffected (Fig. $1 \mathrm{e})$.

Recently, we described the presence of insulin receptors and its downstream signaling cascade in human astrocytes. To validate that leptin indeed affects tyrosine phosphorylation of the insulin receptor we performed experiments in cells treated with insulin, leptin and leptin followed by insulin. Thereby, insulin increased tyrosine phosphorylation of the insulin receptor which was absent when cells were preincubated with leptin. In addition, leptin led to an increase in serine phosphorylation in insulin receptor substrate 1 (Fig. 1f) which was shown to mediate insulin resistance in various tissues [7]. To evaluate the effect of leptin on insulin action, time and dose-response experiments were performed. Thereby, it became evident that leptin pretreatment impaired phosphorylation of Akt as early as 30 minutes, and the inhibitory effect persisted for up to 24 hours (Fig. 2a). In terms of dose, low leptin concentrations were not able to inhibit phosphorylation of Akt, while leptin in a range as present in obese was able to impair P-Akt473 (Fig. 2b).

To investigate whether leptin is able to inhibit insulin action in vivo, Western Blot analysis in brain tissues of mice was performed. Insulin significantly increased tyrosine phosphorylation of its receptor by $316 \pm 34 \%(p<0.01, n=4)$, as well as Irs 2 by $285 \pm 46 \%$ (Fig. $3 \mathrm{a}, p<0.01, \mathrm{n}=4$ ). When leptin was injected prior to insulin, tyrosine phosphorylation of the insulin receptor was reduced to $185 \pm 47 \%$ of basal and to $167 \pm 44 \%$ for Irs2 $(p<0.01$, $\mathrm{n}=4$ ). This went along with impaired phosphorylation of Akt473 in insulin-stimulated mice that were pretreated with leptin. To verify adequate leptin action in the brain, phosphorylation levels of Stat 3 were evaluated. As expected, leptin treatment dramatically increased phosphorylation of Stat3 in brain tissues while insulin was ineffective (Fig. 3b).

We lately identified an insulin-mediated increase in locomotor activity as a measure of insulin sensitivity in the brain which is absent in obese mice and further promotes physical inactivity [4]. Therefore, insulin and leptin were applied into the cerebrospinal fluid (icv) of mice. Locomotor activity was significantly improved by insulin while leptin inhibited activity in vivo. Leptin application prior to insulin abolished the insulin-mediated increase in locomotor activity (Fig. 3c). By contrast, the application of a murine leptin antagonist icv decreased locomotor activity by $\sim 48 \pm 5 \%(p<0.001 ; n=6)$, suggesting that leptin levels in the physiological range are needed to maintain locomotion and keep the balance between food intake and energy expenditure (Fig. 3c). The effect of leptin and insulin was again verified by Western Blot analysis in brain tissues and demonstrated that the leptin antagonist was not able to affect insulin receptor phosphorylation in lean mice (Fig. 3d). 
Fig. 3. Leptin impairs insulin signalling in the mouse brain. a Tyrosine phosphorylation of the insulin receptor and insulin receptor substrate 2 in total brain lysates following injection of leptin, insulin or leptin followed by insulin. For quantification please see result section. b Phosphorylation of Akt, Gsk and Stat3 in total brain lysates following intravenous injection of insulin, leptin or leptin followed by insulin. The membranes were reprobed with an anti-Akt antibody to ensure equal loading. One representative Western Blot is shown out of three independent experiments. c Locomotor activity (counts/min) in overnight fasted

a

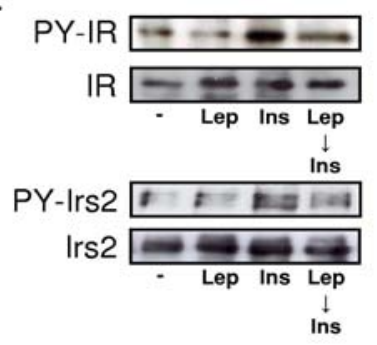

b

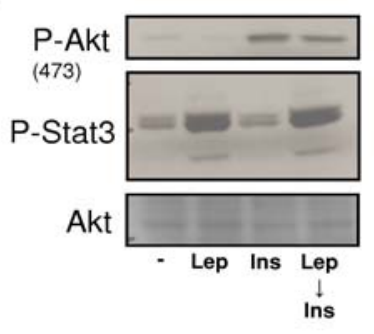

$\mathrm{C}$.

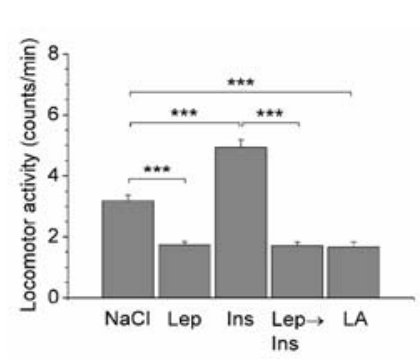

d

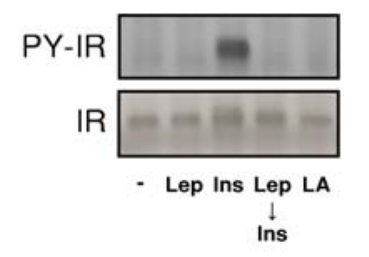

mice following icv application of $\mathrm{NaCl}$ as inter-individual control, human insulin (3.75 $\mathrm{mU}$ in total), leptin $(10 \mu \mathrm{g} / 5 \mu \mathrm{l})$, and human insulin $(3.75 \mathrm{mU})$ after $30 \mathrm{~min}$ pretreatment with leptin $(10 \mu \mathrm{g}$ in total). Data are mean \pm SEM. Significant differences are indicated as follows: ${ }^{* *} p<0.001 ; n=6-14$ /group. d Tyrosine phosphorylation of the insulin receptor in total brain lysates following injection of leptin, insulin, leptin followed by insulin or leptin antagonist (LA). One representative immunoblot out of three independent experiments is shown.

Fig. 4. Human characteristics and desire to move during a hyperinsulinemic euglycemic clamp. a C-reactive protein (CRP) and adiponectin in lean (black, $n=14$ ) and obese (grey, $n=30-31$ ) individuals before the hyperinsulinemic euglycaemic clamp; ${ }^{* * *} p<0.001$. b Increase in plasma insulin levels in lean (black, $n=14$ ) and obese (grey, $n=31$ ) individuals before and after the hyperinsulinemic euglycemic clamp; ${ }^{* *} p<0.005 ;{ }^{* * *} p<0.001$. c Increase in desire to move in a visual analog scale measurement during a hyperinsulinaemic euglycaemic clamp in lean (black, $n=14$ ) and obese (grey, $n=31$ ) human subjects. The desire to move increased in lean but not

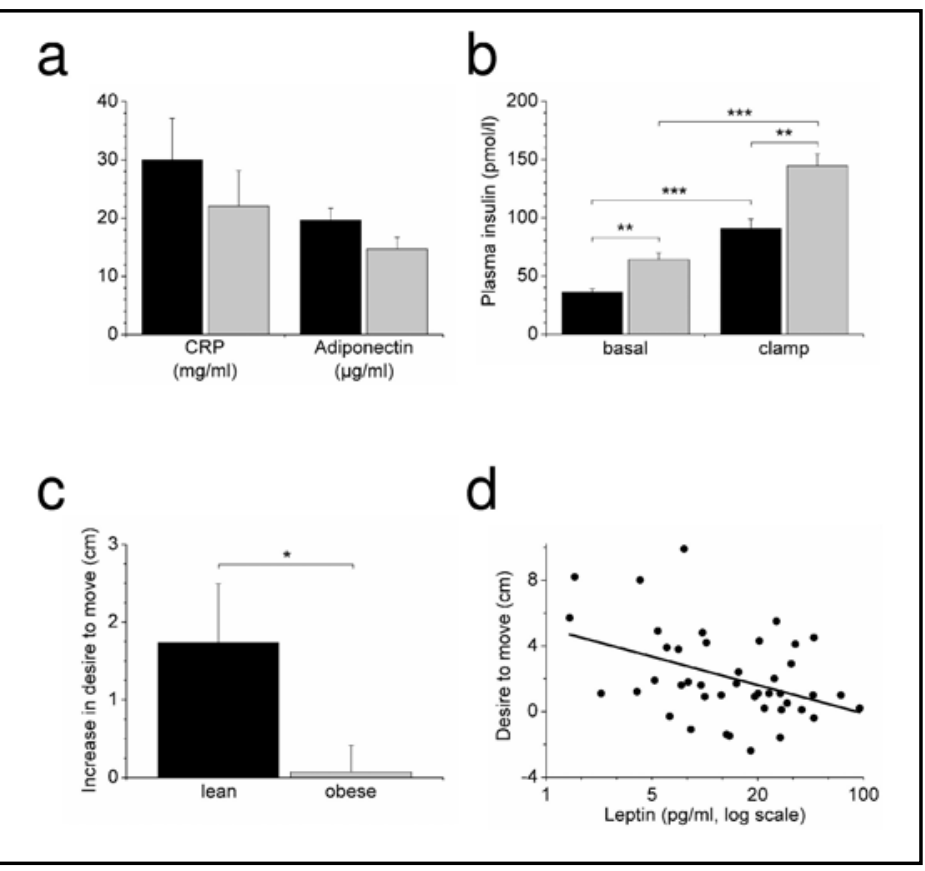
in obese volunteers ( $p=0.026$ lean vs. obese). For subject characteristics see method section. d Negative correlation between the insulin-mediated desire to move and basal leptin levels $(\mathrm{r}=-0.48, p=0.001)$.

Without doubt, the pathophysiological relevance of impaired insulin action in the brain on locomotor activity in humans is hard to detect. To proceed in this respect, healthy lean and obese volunteers underwent a hyperinsulinaemic-euglycaemic clamp and insulin-dependent 


\section{Cellular Physiology Cell Physiol Biochem 2012;30:238-246 \\ \begin{tabular}{ll|l} 
and Biochemistry & $\begin{array}{l}\text { DOI: 10.1159/000339060 } \\
\text { Published online: June 19, } 2012\end{array}$ & $\begin{array}{l}\text { C 2012 S. Karger AG, Basel } \\
\text { www.karger.com/cpb }\end{array}$ \\
\cline { 2 - 3 } Sartorius/Heni/Tschritter et al.: Leptin and Insulin Action in Brain
\end{tabular}}

changes in the desire to move were analysed by a visual analog scale rating. Lean and obese volunteers displayed comparable plasma adiponectin and c-reactive protein levels (Fig. 4a), while fasting insulin and leptin concentrations were significantly higher in obese (Fig. 4b and for subject characteristics please see method section). Applying this approach to both groups, plasma insulin levels during the clamp increased by 2.7 -fold in lean and 2.5 -fold in obese individuals (Fig. 4b). Whereas the desire to move was significantly increased in lean individuals during insulin infusion $(p<0.05)$ it was indistinguishable in obese (Fig. 4c). Moreover, leptin levels at the beginning of the clamp were shown to be a negative predictor for the desire to move during the clamp ( $p=0.001)$, and remained significant after adjustment for sex and BMI $(p<0.05)$ (Fig. $4 \mathrm{~d})$.

\section{Discussion}

The peptide hormone leptin is transported across the blood-brain-barrier and its concentration in the cerebrospinal fluid is elevated in obese [21]. While fasting substantially decreases plasma as well as CSF leptin levels in lean, the fasting-induced decrease in leptin levels is abolished in obese [22]. Therefore, leptin represents a permanent adiposity-related signal to the brain, while physical exercise and food restriction modulates leptin sensitivity in diet-induced obese rats [23]. Most of the previous work has been done in leptin-deficient mice and humans. Herein, a complete loss of leptin in early life resulted in an obese phenotype due to alterations in energy homeostasis and food intake, and leptin replacement therapies restored the metabolic balance towards a healthy phenotype. In line with this, a loss of leptin action by the antagonist decreased locomotor activity in our model and suggested that fluctuation in leptin levels within a physiological range are of great importance to maintain a healthy, physically active phenotype.

On the other hand, elevated leptin levels are a negative regulator of insulin action [7, 24], and our work demonstrated that in the presence of hyperleptinemia in the brain, insulin signalling is impaired at the molecular, functional and behavioural level. In line with this, a recent study in rats provided evidence for leptin to promote weight gain in diet-induced obese rats [25]. Besides its impact on insulin signalling, leptin per se is able to inhibit locomotor activity which suggested an additional insulin-independent action of leptin on locomotion. This is in accordance with the fact that locomotor activity is increased in rats that lack leptin receptors in the ventral tegmental area by using RNAi [26].

At the cellular level, leptin becomes important in regulating neuronal activity by the activation of large conductance $\mathrm{Ca}^{2+}$-activated $\mathrm{K}^{+}$channels which results in depression of excitatory synaptic transmission [27]. Besides leptin's action on neuronal networks that control feeding, energy balance, and neurotransmission, nonneuronal cellular effects of leptin in the central nervous system were recently identified. In vivo studies in mice demonstrated that adult-onset obesity is associated with region-specific upregulation of astrocytic leptin receptors [20], and leptin treatment was shown to affect calcium flux in astrocytes [28].

Here, we show that on the cellular level, elevated leptin impairs insulin action in astrocytes that is accompanied by a decrease in glycogen synthesis. While the direct role of astrocytes for synaptic transmission is still an open question, their response to alterations in energy metabolism and substrate availability is unquestionable. Astrocytes are able to detect metabolic changes that may affect brain homeostasis. Therefore, they play a crucial role for brain function.

In our study, elevated leptin levels as present in obese affect insulin action and glycogen formation suggesting that leptin represents an obesity-related signal from the periphery to the brain and finally alters brain activity and locomotion. However, it is yet to be determined how neuronal and astrocytic leptin and insulin signalling act together in pathophysiological conditions like obesity.

In conclusion, leptin lowers insulin action in astrocytes and in brain tissues which is accompanied by reduced locomotor activity. In view of these data, elevated leptin levels as present in obese patients or achieved by leptin agonists might be harmful while approaches 


\title{
Cellular Physiology \\ Cell Physiol Biochem 2012;30:238-246 and Biochemistry \begin{tabular}{l|l}
\hline DOI: 10.1159/000339060 & C 2012 S. Karger AG, Basel
\end{tabular} \\ \begin{tabular}{l|l} 
Published online: June 19, 2012 & www.karger.com/cpb \\
\hline
\end{tabular} \\ Sartorius/Heni/Tschritter et al.: Leptin and Insulin Action in Brain
}

to keep leptin in the brain within the physiological range might be beneficial to promote physical activity and finally weight loss.

\begin{abstract}
Abbreviations
icv (intracerebroventricular); IR (insulin receptor); CSF (cerebrospinal fluid).
\end{abstract}

\section{Acknowledgements}

We are grateful to the people who participated in the clamp studies. Further, we acknowledge the excellent technical assistance made to the study by E. Metzinger, D. Neuscheler, A. Janessa, and L. Nono, A. Bury, E. Kollmar, M. Borutta and G. Walker. This study was supported in part by grants from the Deutsche Forschungsgemeinschaft (FR 1561/4-1, HE 3653/3-1) and a grant from the German Federal Ministry of Education and Research (BMBF) to the German Center for Diabetes Research (DZD e.V.).

\section{Conflict of interest statement}

The authors declare that there is no duality of interest associated with the manuscript.

\section{References}

1 Taguchi A, Wartschow LM, White MF: Brain IRS2 signaling coordinates life span and nutrient homeostasis. Science 2007;317:369-372.

2 Lin X, Taguchi A, Park S, Kushner JA, Li F, Li Y, White MF: Dysregulation of insulin receptor substrate 2 in beta cells and brain causes obesity and diabetes. J Clin Invest 2004;114:908-916.

3 Bruning JC, Gautam D, Burks DJ, Gillette J, Schubert M, Orban PC, Klein R, Krone W, Muller-Wieland D, Kahn CR: Role of brain insulin receptor in control of body weight and reproduction. Science 2000;289:21222125.

4 Hennige AM, Sartorius T, Lutz SZ, Tschritter O, Preissl H, Hopp S, Fritsche A, Rammensee HG, Ruth P, Haring HU: Insulin-mediated cortical activity in the slow frequency range is diminished in obese mice and promotes physical inactivity. Diabetologia 2009;52:2416-2424.

5 BodenG: Interaction between free fatty acids and glucose metabolism. Curr Opin.Clin Nutr Metab Care 2002;5:545-549.

6 Milanski M, Degasperi G, Coope A, Morari J, Denis R, Cintra DE, Tsukumo DM, Anhe G, Amaral ME, Takahashi HK, Curi R, Oliveira HC, Carvalheira JB, Bordin S, Saad MJ, Velloso LA: Saturated fatty acids produce an inflammatory response predominantly through the activation of TLR4 signaling in hypothalamus: implications for the pathogenesis of obesity. J Neurosci 2009;29:359-370.

7 Hennige AM, Stefan N, Kapp K, Lehmann R, Weigert C, Beck A, Moeschel K, Mushack J, Schleicher E, Haring HU: Leptin down-regulates insulin action through phosphorylation of serine-318 in insulin receptor substrate 1. FASEB J 2006;20:1206-1208.

8 Perez C, Fernandez-Galaz C, Fernandez-Agullo T, Arribas C, Andres A, Ros M, Carrascosa JM: Leptin impairs insulin signaling in rat adipocytes. Diabetes 2004;53:347-353.

9 Zimmet PZ, Collins VR, de Court Hodge AM, Collier GR, Dowse GK, Alberti KG, Tuomilehto J, Hemraj F, Gareeboo H, Chitson P, Fareed D: Is there a relationship between leptin and insulin sensitivity independent of obesity? A population-based study in the Indian Ocean nation of Mauritius. Mauritius NCD Study Group. Int J Obes Relat Metab Disord 1998;22:171-177. 


\section{Cellular Physiolosy Cell Physiol Biochem 2012;30:238-246

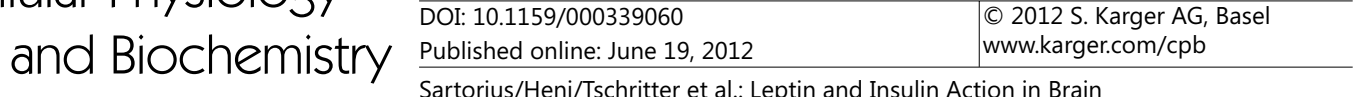 Sartorius/Heni/Tschritter et al.: Leptin and Insulin Action in Brain}

10 Tschritter O, Preissl H, Hennige AM, Sartorius T, Grichisch Y, Stefan N, Guthoff M, Dusing S, Machann J, Schleicher E, Cegan A, Birbaumer N, Fritsche A, Haring HU: The insulin effect on cerebrocortical theta activity is associated with serum concentrations of saturated nonesterified Fatty acids. J Clin Endocrinol Metab 2009;94:4600-4607.

11 Caro JF, Kolaczynski JW, Nyce MR, Ohannesian JP, Opentanova I, Goldman WH, Lynn RB, Zhang PL, Sinha MK, Considine RV: Decreased cerebrospinal-fluid/serum leptin ratio in obesity: a possible mechanism for leptin resistance. Lancet 1996;20;348:159-161.

12 Ahima RS, Kelly J, Elmquist JK, Flier JS: Distinct physiologic and neuronal responses to decreased leptin and mild hyperleptinemia. Endocrinology 1999;140:4923-4931.

13 Cohen B, Novick D, Rubinstein M: Modulation of insulin activities by leptin. Science 1996;274:1185-1188.

14 Szanto I, Kahn CR: Selective interaction between leptin and insulin signaling pathways in a hepatic cell line. Proc Natl Acad Sci USA 2000;97:2355-2360.

15 Berthou F, Rouch C, Gertler A, Gerozissis K, Taouis M: Chronic central leptin infusion differently modulates brain and liver insulin signaling. Mol Cell Endocrinol 2011;337:89-95.

16 Nedergaard M, Verkhratsky A: Artifact versus reality-How astrocytes contribute to synaptic events? Glia 2012;60:1013-1023.

17 Heni M, Hennige AM, Peter A, Siegel-Axel D, Ordelheide AM, Krebs N, Machicao F, Fritsche A, Haring HU, Staiger H: Insulin promotes glycogen storage and cell proliferation in primary human astrocytes. PLoS ONE 2011;6:e21594.

18 Niv-Spector L, Gonen-Berger D, Gourdou I, Biener E, Gussakovsky EE, Benomar Y, Ramanujan KV, Taouis M, Herman B, Callebaut I, Djiane J, Gertler A: Identification of the hydrophobic strand in the A-B loop of leptin as major binding site III: implications for large-scale preparation of potent recombinant human and ovine leptin antagonists. Biochem J 2005;391:221-230.

19 Harris RB, Zhou J, Redmann SM, Jr, Smagin GN, Smith SR, Rodgers E, Zachwieja JJ: A leptin dose-response study in obese (ob/ob) and lean (+/?) mice. Endocrinology 1998;139:8-19.

20 Pan W, Hsuchou H, He Y, Sakharkar A, Cain C, Yu C, Kastin AJ: Astrocyte leptin receptor (ObR) and leptin transport in adult-onset obese mice. Endocrinology 2008;149:2798-2806.

21 Schwartz MW, Peskind E, Raskind M, Boyko EJ, Porte D Jr: Cerebrospinal fluid leptin levels: relationship to plasma levels and to adiposity in humans. Nat Med 1996;2:589-593.

22 O'Doherty RM, Nguyen L: Blunted fasting-induced decreases in plasma and CSF leptin concentrations in obese rats: the role of increased leptin secretion. Int J Obes Relat Metab Disord 2004;28:173-175.

23 Ropelle ER, Flores MB, Cintra DE, Rocha GZ, Pauli JR, Morari J, De Souza CT, Moraes JC, Prada PO, Guadagnini D, Marin RM, Oliveira AG, Augusto TM, Carvalho HF, Velloso LA, Saad MJ, Carvalheira JB: IL-6 and IL-10 antiinflammatory activity links exercise to hypothalamic insulin and leptin sensitivity through IKKbeta and ER stress inhibition. PLoS Biol 2010; 24:8e1000465.

24 Sweeney G, Keen J, Somwar R, Konrad D, Garg R, Klip A: High leptin levels acutely inhibit insulin-stimulated glucose uptake without affecting glucose transporter 4 translocation in 16 rat skeletal muscle cells. Endocrinology 2001;142:4806-4812.

25 Shapiro A, Matheny M, Zhang Y, Tumer N, Cheng KY, Rogrigues E, Zolotukhin S, Scarpace PJ: Synergy between leptin therapy and a seemingly negligible amount of voluntary wheel running prevents progression of dietary obesity in leptin-resistant rats. Diabetes 2008;57:614-622.

26 Hommel JD, Trinko R, Sears RM, Georgescu D, Liu ZW, Gao XB, Thurmon JJ, Marinelli M, DiLeone RJ: Leptin receptor signaling in midbrain dopamine neurons regulates feeding. Neuron 2006;51:801-810.

27 Shanley LJ, Irving AJ, Rae MG, Ashford ML, Harvey J: Leptin inhibits rat hippocampal neurons via activation of large conductance calcium-activated $\mathrm{K}^{+}$channels. Nat Neurosci 2002;5:299-300.

28 Hsuchou H, Pan W, Barnes MJ, Kastin AJ: Leptin receptor mRNA in rat brain astrocytes. Peptides 2009;30:22752280. 